\title{
Alüminyum-Magnezyum-Zirkonyum Alaşımına Grafen-Nano Karbon Esaslı Takviyelerin, Fiziksel ve Mekanik Özelliklere Etkisinin İncelenmesi
}

\author{
Levent Cenk Kumruoğlu \\ Sivas Cumhuriyet Üniversitesi, Mühendislik Fakültesi, Metalürji ve Malzeme Müh. Bölümü, Sivas, Türkiye \\ ${ }^{1}$ kumru@cumhuriyet.edu.tr,
}

Araştırma Makalesi

Geliş Tarihi: 18.07 .2018

Kabul Tarihi: 10.10 .2018

$\ddot{O} \mathbf{z}$

$\mathrm{Bu}$ çalışmada, metal-karbon nano-kompozit üretimi hedeflenmiştir ve katkı malzemesi olarak kullanılacak olan nano-karbon formları (grafen), elektro eksfoliasyon yöntemiyle üretilmiştir. Üretilmiş olan grafen, alkol ve polimer bazlı çözücülerde çözülüp, hidrofilik özellik elde edilmiştir takiben metal tozları bu çözeltiye ilave edilerek homojen bir Grafen-Metal tozu karışımı elde edilmiştir. Üretilmiş olan bu karışım tozlar direkt olarak tek eksenli pres ve soğuk isostatik pres ile peş peşe preslenmiştir, daha sonra argon ve azot atmosferinde sinterlenmiş ve nihai olarak da mikroyapı tekstürü, mekanik (sertlik, v.b) ve fiziksel özellikler (porozite, yoğunluk) ölçülmüştür ve karakterizasyon sonuçları tartışılmıştır. İlave edilen ağ..\%3 Mg ve \%1 Zr, Alüminyumun başlangıç sertlik değerini 20-30 Hv den 80 HV ye yükselmiştir. Artan pres kuvveti ve artan sinterleme sicaklığına bağlı olarak sertliğin $80 \mathrm{HV}$ ve üzeri seviyelerine yükseldiği ölçülmüştür ancak belirli bir değerden sonra mekanik değerlerde azalma olduğu ölçülmüştür. $\mathrm{Bu}$ alaşıma ilave edilen ağ.\% 0.05, 0.15, 0.3, $0.45 \mathrm{~g}$ grafen takviyesi de yine sertlikte ve mukavemette artış sağlamıştır. Sertlik ve mukavemet değeri sırası ile $100 \mathrm{HV}$ ve $250 \mathrm{MPa}$ daha üst değerlere üzerine yükselmiştir. Grafenin üretimi, kompozit takviye yöntemi ve sinterleme süreci ile ilgili sistematik yeni bir yöntem elde edilmiştir ve bunun sonucunda grafen ilave edilmesinin, matris içinde dolgu etkisi yaparak, mukavemet ve sertlik değerlerinde artışa yol açtı̆̆ı gözlenmiştir. Ayrıca grafen takviyeli, Al-3Mg-1Zr alaşımda aşınma direncinin artığı gözlemlenmiş ve toz sıkıştırma sürecinde sürtünmenin azaldığ ve sıkıştırılabilirliğin arttığı tespit edilmiştir. Böyle bir sonucun özellikle ekstrüzyon veya derin çekme gibi işlemlerde, şekil verme işlemleri sırasında sürtünme kuvvetlerini azaltarak ve deformasyon kabiliyetini artırarak, mühendislik fayda sağlayacağına inanılmaktadır.

Anahtar Kelimeler: Al-Mg3-1Zr Alaşımı, Grafen, Hafif Alaşımlar, Nanokompozit, Mekanik Özellikler

\section{Investigation of the Effect of Graphene-Nano Carbon Based Reinforcement on Physical and Mechanical Properties Added to Aluminum-Magnesium-Zirconium Alloy}

\author{
Levent Cenk Kumruoğlu \\ Sivas Cumhuriyet University, Engineering Faculty, Dept. Of. Metallurgy and Materials, Sivas, Turkey \\ 'kumru@cumhuriyet.edu.tr
}

\begin{abstract}
In this work, metal-carbon nanocomposite production is targeted and nanocarbon forms (graphene) to be used as additive material are produced by electro exfoliation method. The produced graphene was dissolved in alcohol and polymer-based solvents to obtain a hydrophilic property, followed by the addition of metal powders to this solution to obtain a homogeneous Grafen-Metal powder mixture. This powder mixture is directly pressed by single-axis press and cold isostatic press, then sintered in argon and nitrogen atmosphere and finally microstructure textural, mechanical (hardness, etc.) and physical properties (porosity, density) are measured and characterization the results are discussed. The added wt. $\% 3 \mathrm{Mg}$ and $1 \% \mathrm{Zr}$ increased the initial hardness value of Aluminum from 20 to $30 \mathrm{Hv}$ to $80 \mathrm{HV}$. It has been measured that the hardness increases to $80 \mathrm{HV}$ and above depending on the increased pressing force and the increased sintering temperature, but a decrease in mechanical values is measured after a
\end{abstract}

*Sorumlu Yazar: Sivas Cumhuriyet Üniversitesi, Mühendislik Fakültesi, Metalürji ve Malzeme Müh. Bölümü, Sivas, Türkiye; kumru@cumhuriyet.edu.tr 
certain value. The graphene reinforcement added to this alloy at wt $\% 0.05,0.15,0.3,0.45 \mathrm{~g}$ also provided increased hardness and strength. The hardness and strength values increased above the values of $100 \mathrm{HV}$ and $250 \mathrm{MPa}$, respectively. A systematic new method of graphene production, composite reinforcement method and sintering process has been obtained and it has been observed that the addition of graphene causes a filling effect in the matrix, leading to an increase in strength and hardness values. In addition, it was observed that wear resistance in $\mathrm{Al}-3 \mathrm{Mg}-1 \mathrm{Zr}$ alloy with graphene reinforcement was observed to be increased, and in the powder compacting process, friction decreased and compressibility increased. Such a result is believed to provide engineering benefit, particularly in extrusion or deep drawing, by reducing the frictional forces and increasing the deformation capability during forming operations.

\section{Keywords: Al-Mg3-1Zr Alloy, Graphene, Light Alloys, Nanocompoziet, Mechanical Properties}

\section{GİRIŞ}

Otomotiv endüstrisinde kullanılan metal ve alaşımlarının mevcut dayanımdan ödün vermeden hafifletilmesi, gerek $\mathrm{CO}_{2}$ salınımı (2020 Hedefi $95 \mathrm{~g} \mathrm{CO}_{2} / \mathrm{km}$ ) gerekse yakıt tüketiminin azaltılması açısından yasal düzenlemelere bağlı olarak Avrupa ve Amerika'da en önemli araştırma konularından birini oluşturmaktadır. Bu bağlamda birçok üniversite ve otomotiv sanayi tarafından araştırmalar yapılmaktadır. Yapılan araştırmalar, tasarım, hafif metaller ve karbon tabanlı malzemeler üzerine yoğunlaşmaktadır. Hafif metaller üzerine olan çalışmalarda adres olarak Ti, Al ve $\mathrm{Mg}$ alaşımları, bunların kompozit uygulamaları ve alternatif üretim teknolojileri ön plana çıkmaktadır [1]. Bunun sonucu olarak otomotiv endüstrisi, son yıllarda yenilikçi malzeme arayışlarına yönelmiştir ki bunun sonucunda vazgeçilmez olan en önemli özellikler arasında hafiflik, yüksek spesifik mukavemet, iyi korozyon direnci, şekil verilebilirlik, dekoratif görsellik, geri dönüşüme uygunluk gelmektedir. $\mathrm{Bu}$ vazgeçilmez özellikler Alüminyum (Al) ve alaşımlarında toplanmaktadır [2]. Alüminyum alaşımlarından daha hafif bir metal alaşımı olan Magnezyum (Mg) ve Mg alaşımları da mükemmel spesifik mukavemet, ses sönümleme kapasitesi, döküle bilirlik, tekrar kullanılabilirlik özellikleri ile yine cazibeli bir metal olarak ön plana çıkmaktadır [3,4]. Yukarıda hafiflik, dayanımın ve ekonomikliğin üçlü olarak değerlendirilmesi sonucu titanyumun yüksek maliyeti nedeni ile otomotiv sektöründe kullanılmadığı ve yine korozyon dayanımındaki bariz üstünlüğü nedeni ile $\mathrm{Al}$ alaşımları üzerine yoğunlaşmanın rasyonel bir tercih olacağı düşünülmektedir. Ancak burada hangi üretim yönteminin veya hangi elementlerin ne oranda seçilmesi sorusu ortaya çıkmaktadır. Jenerik bir malzeme bilgisi, saf metallerin alaşım elementi ilavesi ile mukavemetlerinin artırabileceğidir. $\mathrm{O}$ halde $\mathrm{Al}$ içerisine yine hafif olan $\mathrm{Mg}$ ile alaşımlama doğru bir tercih olacaktır, nitekim alaşım elementleri ilavesi latis içerisinde "pinning" mekanizması gereği dislokasyon hareketini engelleyerek mukavemet artırmaktadır. Al-Mg alaşımında çözünürlük sınır1 $450{ }^{\circ} \mathrm{C}$ de $\% 17.4 \mathrm{Mg}$ şeklindedir ve bir solvüs eğrisi içermektedir aynı zamanda $\mathrm{Al}_{3} \mathrm{Mg}_{2}$ ve $\mathrm{Al}_{12} \mathrm{Mg}_{17}$ gibi intermetalik yapı oluşumları söz konusudur [5]. Bu durum Mg'un çok geniş bir aralıkta alaşım elementi olarak kullanılabileceğini ve çözeltiye alınıp çökelme sertleşmesi ile mukavemet artırma termal işleminin mümkün olduğunu işaret etmektedir. Ancak genel anlamda 5000 serisi alaşımların $\mathrm{Mg}$ içerikleri incelendiğinde, $\mathrm{Mg}$ ilavesinin Al'un intirinsik bir malzeme özelliği olan Stacking fault enerjisini, $200 \gamma\left(\mathrm{mJ} \mathrm{m}^{-2}\right)$ den $30 \gamma\left(\mathrm{mJ} \mathrm{m}^{-2}\right)$ değerlerine kadar düşürmektedir (MorishigeaT,2011). $\mathrm{Bu}$ düşüş malzemeni sürtünme ve galling direncini artırmakta ve aynı zamanda ergime veya toz metalürjisi boyutundan bakarsak sinterleme sıcaklığını düşürecektir. $\mathrm{Mg}$ ilavesinin artması \%6 ya kadar olabilmekte bu durumda üçüncü bir alaşım elementi ilavesi, Al-Mg intermetaliklerinin azaltılması ve keskin köşeli yapı veya tane sınır birikmelerini önlemek maçıyla kaçınılmaz olmaktadır. Yine bir diğer problem ise $\mathrm{Mg}$ un oksijene olan yüksek afinitesine bağlı olarak meydana gelen oksitlenme problemi ve ergitme güçlüğü olarak ortaya çıkmaktadır. Nitekim Mg alaşımlarının dökümü ve 1sıl işlemi çoğunlukla atmosfer kontrollü hatta ağır elektrik kesme gazları kullanarak gerçekleşmektedir. Aksi takdirde izabe işlemi yeteri kadar verimli olmayıp, MgOAl2O3 gibi oksidasyon ürünleri sıvı banyoya veya tane içlerine yerleşmektedir. O halde Mg ilavesi için \%2-4 Aralığı ideal görünmektedir. $\mathrm{Bu}$ sebeple bu çalışmada $\mathrm{Al}$ içine ilave edilen $\mathrm{Mg}$ seviyesi ağ.\% 3 olarak tercih edilmiştir. Ancak üçüncü bir alaşım elementi ilavesi ile çözünürlük sınırlarında ince disperse olmuş yeni intermetalik fazlar veya çökeltilerin elde edilmesi ile ilgili bilinen bir uygulama ise $\mathrm{Al}-\mathrm{Mg}$ alaşımına karbon ilavesidir.

Son yıllarda $\mathrm{Mg}$-Al alaşımlarına Al-C master alaşımı şeklinde tane inceltme ile ilgili çalışmalar yapılmış, $\mathrm{Al}(\mathrm{c})$ $\mathrm{Al}_{4} \mathrm{C}_{3}$ formunda karbürlerin oluştuğu ve tercihen tane sınırlarında biriktiğgi, ve \%1 ila \%2.5 arasında kullanıldığı ve artan tane inceltici oranına bağlı olarak, tanelerin inceldiği Epma analizleri ile detekte edilmiştir [6]

İlave edilen Al-C master alaşımının, ergimiş Al içinde aşağıdaki reaksiyona göre $705{ }^{\circ} \mathrm{C}$ 'de oluştuğu iddia edilmektedir.

$$
\mathrm{Al}(\mathrm{l})+\mathrm{C}(\mathrm{s}) \rightarrow \mathrm{Al}_{4} \mathrm{C}_{3}(\mathrm{~s})
$$

Burada, aşılama (tane inceltme) işleminin döküm ile yapılması sonucu dentritik bir yapı husule gelmiş olsa da, master alaşım sıvı metal bünyesinde 30 dakika süre ile bekletilip, daha sonra karıştırılması gerekmektedir veya döküm esnasında akan metale ilave edilmelidir. Bu iki sistemde gerek çözünen gaza bağlı oksidasyon - segregasyon ve tekrarlanabilirlik açısından riskler taşımaktadır. Özellikle otomotiv sektörü gibi kalite öncelikli sektörlerde limitler içinde ürün üretmek için çok fazla deneme yanılmaya sebep verecek veya yüksek oranda fireli imalat yapılacaktır. Bunlar ise ürünü ekonomik olmaktan uzaklaştıracaktır. Ancak, 
EPMA analizleri detaylı incelendiğinde, tanelerin kavşakları arasında çözünmüş karbonun yerleştiği anlaşılmakta ve bunun kontrol edilebilirliği açısından master alaşım hazırlanmasında Toz metalürjisi yöntemi uygulanmaktadır. Toz metalürjisi ile baştan sona kadar karbon takviyeli bir Kompozit üretimi, daha kontrol edilebilir bir proses olup, grafit yerine nano-grafen $(\mathrm{G})$ veya karbon tüplerin (CNT) kullanılabilme olasılığı artacaktır. Nitekim döküm yönteminde ilave edilen grafenin gerek homojen dağılma sorunu ve gerekse yüksek sıcaklıklarda oksijenle reaksiyona girerek oksitlene ve hatalı bir yapıya dönüşme sorunu ortaya çıkmaktadır. Bu durum maalesef göz ardı edilmekte ve grafenin termal stabilitesinin $500{ }^{\circ} \mathrm{C}$ den itibaren bozulmaya başlaması [7] sonucu güçlendirici olması amacı ile ilave edilen grafen bir fayda sağlamakta, hatta oksijenle reaksiyona girerek gaz formu oluşturabilmektedir. Grafenin termal dekompozisyonu Raman spektral analiz aracılığı ile izlenebilmektedir.

$\mathrm{Bu}$ çalışmada toz metalürjisi yöntemi ile $\mathrm{Al}-3 \mathrm{Mg}-1 \mathrm{Zr}$ alaşımı $\% 0.05, \% 0.15, \% 0.3$ ve $\% 0.45$ nano-grafen ile takviye edilerek fiziksel ve mekanik özellikleri incelenmiştir. Toz metalürjisi ve Grafen üretimindeki izlenen yöntemlerinin tercih edilme nedenleri ise makale boyunca gerekçelendirilmiştir. Yüzyılın malzemesi olarak adlandırılan grafen, sp2 bağlı karbon atomlarından oluşmuş, bir atom kalınlığında 2-boyutlu (2D) planar bir tabakadır. Olağanüstü mekanik, elektrik, termal ve optik özellikleri ile bilimde çığır açan ve başlıca materyal bilimi, nanoelektronik ve yoğun madde fiziği sahasında önem kazanan grafen, grafitin, nanotüpün ve C60'1n asıl yapıtaşı olan karbon allotropudur. Grafenin muhteşem özellikleri, asıl olarak karbon atomlarının iki boyutlu altıgen bir yapıda dizilmiş bu formundan kaynaklanmaktadır. Grafene dayalı malzemeler doğal olarak toksik olmayıp, kimyasal ve termal olarak toleranslı ve mekaniksel yönden de güçlüdürler. Grafen, yapısında göreceli hızlarda elektron hareketine izin veren elektron tünellemenin gerçekleşmesi sebebiyle üstün elektriksel iletkenlik ve yüksek bir yük-taşıyıcı hareketliliği sergilemektedir (20 m2V-1s-1). Ayrıca çok yüksek bir spesifik yüzey alanına (2630 m2g-1, gram başına yarım bir futbol sahası alanına benzetilecek bir büyüklüktedir), mükemmel mekanik güce ve sertliğe (Young modülü 1.0 $\mathrm{TPa})$, iyi elastisiteye, 1s1l kondüktiviteye ( $\sim 5000 \mathrm{Wm}-1 \mathrm{~K}-1)$, üstün 1sıl iletkenliğe, yüksek geniş bir elektrokimyasal pencereye sahiptirler ve hem optik transparanlık ( \% 97.7) hem de yüksek elektriksel iletkenlik sunabilmektedirler $[8,9]$. Grafen ve türevleri başlıca enerji-depolanması ve enerji dönüşüm materyalleri, 1sıl ve elektriksel olarak iletken güçlendirilmiş nanokompozitler, nanoelektronikler ve sensörler gibi birçok uygulama alanında gelecek vaat eden bileşenlerdir [10].

Bahsi geçen bu mühendislik uygulamaları grafenin büyük ölçekte elde edilebilmesini gerektirmekte ve bu sebeple buna uygun etkili metodların geliştirilmesi gerekmektedir. Literatürde günümüze kadar farklı çalışma gruplarınca grafen, grafen oksit nano-plaka ve nano-şerit üretiminde kullanılan ve/ya önerilen sentezler 3 farklı yöntem başlığ altında toplanmaktadır. Bunlar, kimyasal buhar çöktürme metodu, grafit oksidin eksfoliasyonu ve elektrokimyasal sentezleme yöntemleridir. Diğer sentezleme metotları da rapor edilmesine rağmen, GO grafit tozlarından literatürde genellikle Hummers' veya modifiye Hummers' metoduyla sentezlenmektedir [11]. Grafit oksit üretmek için grafitin elektrokimyasal oksidasyonu ve GNs (grafen nano plakalar) üretmek için indirgenmesini takiben eksfoliasyonun, kimyasal oksidasyonu takiben yüksek sicaklıkta indirgenmeyle hazırlanan grafen nano plakalarından daha üstün elektriksel özelliklere sahip olduğu rapor edilmiştir. Elektrokimyasal olarak eksfoliye grafen nano-plakalardan yapılan geçirgen iletken filmler mükemmel bir iletkenlik sergilemektedirler (\% $\% 6$ geçirgenlikte grafen nano plakaların birim alanı başına plaka direnci $210 \Omega$ 'dur $[12,13]$. Bu makalede kimyasal süreçlere bağlı olarak kullanılan kimyasal ve inorganiklerin sonucu olan kirlenme ve safsızlıklardan etkilenmeden GO sentezlenmesi için, düşük konsantrasyonlardaki asitlerin elektrolit olarak kullanıldığı ve elektrokimyasal olarak çözünme sırasında ultrasonik etki ile ekfoliasyon işleminin ve çözelti içindeki katmanlı grafenin ayrıştığ 1 daha çevreci, daha kolay, daha kısa sürede sonuçlanan elektrokimyasal sentezleme işlemi gerçekleştirilmiştir. Elde edilecek grafitin oksidasyon derecesi de elektrokimyasal sentez sırasında uygulanan voltaj ve elektroliz zamanı ayarlanarak kontrol edilmiştir. Burada elde edilen Grafen plakalar, yukarıda belirtildiği üzere toz metal üretim prensiplerine göre, bulk ürün haline getirilmiş ve karakterize edilmiştir.

\section{MALZEME VE YÖNTEM}

\subsection{Grafen Üretimi}

Çalışmalar, elektrokimyasal eksfoliasyon tekniği kullanılarak yapılmış ve Grafen üretimi, 6 mm çapında 200 mm uzunluğunda \% 99,99 safiyetteki, grafit elektrotların anodik eksfoliasyonu ile sürdürülmüştür. Anot ve katot olarak aynı grafit elektrotlar kullanılmış olup, aralarındaki mesafe $25 \mathrm{~mm}$ olarak belirlenmiştir. Anot olan elektrot elektrolit içine $3 \mathrm{~cm}$, katot ise $6 \mathrm{~cm}$ daldırılıp, yüzey/akım yoğunluğu etkisi hedeflenmiştir. Deneyler 250-500 ml lik cam beherlerde gerçekleştirilmiştir ve üzerleri EPS ile kapatılmıştır. Elektrolitik eksfoliasyon deneylerinde, elektrolit olarak farklı konsantrasyonlarda (\%0.1- \%0.5$\% 0.25$ M konsantrasyonlarında) hazırlanmış Hummers' çözeltisi kullanılmıştır.

$\mathrm{Bu}$ çözelti için $\mathrm{H}_{2} \mathrm{SO}_{4}$ (Sigma-Aldrich,) $\mathrm{H}_{3} \mathrm{PO}_{4}$ (Merck), $\mathrm{H}_{2} \mathrm{O}_{2}$ (Sigma-Aldrich), $\mathrm{KMnO}_{4}, \mathrm{HCl}$ (Sigma-Aldrich)'ten temin edilerek kullanılmıştır.Elektro-eksfoliasyon işlemeleri sırasında anot-katot arasına sonikasyon işlemi yapılmış bu sayede, hem anodun eksfoliasyon işlemi hızlanmış hem de, anottan çoklu katmanlar şeklinde kopan Grafen türleri ayrışmaya devam etmiştir. Asidik konsantrasyonun artması ile de yine 3 lü sinerjik bir eksfoliasyon işlemi yapılmış olup, grafit çubuğun grafene ayrışması, bir hücrede 1-3 g/saat mertebelerine ulaşmıştır. Elektrolitik eksfoliasyon tertibatı Şekil 2 de verilmektedir. 


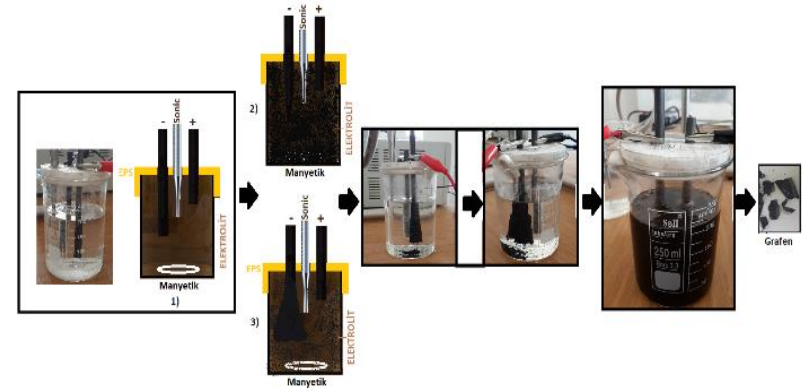

Şekil 1. Elektro-ultrasonik sinerjisi ile grafit elektrotun grafene ayrıştırılması

Elekro eksfoliasyon işlemlerinde anodik olarak bias edilen grafit elektrota $10 \mathrm{~V}-30 \mathrm{~V}$ arasında gerilim uygulanmış ve 1-10 Amper akım çekilmiştir. Sonikasyon işlemleri \% 80 güçte darbeli olarak uygulanmıştır. Sonik işlem her iki elektrot arasına yerleștirilmiș olup hem elektrotlara hem de kopan grafit parçalarına etki göstermiştir. Artan voltaj ile akımın da arttığ1 ve toplamda anottaki azalmanın arttığ gözlemlenmiştir, ancak burada çözünmenin Grafen yaprakları şeklinde değil zaman zaman grafit şeklinde olduğu tespit edilmiştir. Bu durumda Anot grafit Şekil 1'deki 1 numaralı rota ile gösterilen yöntemdekine benzer bir anot çözünme karakteri sergilemiştir. Düşük gerilimlerde ise 2 numaralı eksfoliasyon tipi hakim olmuştur. Artan sonikasyon ve asit konsantrasyonu ile 1 numarada meydana gelen mikronize grafit kopmaları önlemiş, tam bir konik prizma şeklinde katman katma ayrışma gerçekleşmiştir. Sonikasyonun etkisi ile Grafen katmanlarını hem elektrokimyasal etkileşimle hem de elektrolitteki asit ile daha yoğun ve yüzeyli bir temas alanı oluşturulduğu düşünülmektedir. Yine sonik destek ile, akımın sürekli geçişi sağlanmış lokal olarak difüzyona bağlı bir polarizasyonun olması önlenmiştir. Bu sayede lokal aşırı akım çekilmesine bağl1 kopma yarışma gibi çözünme hataları bertaraf edilmiştir. Elektrolit hücresinin üst yüzeyi kapatılarak, elektroliz ürünü gazların sistemden çıkışı yavaşlatılmış ve kısmi bir basınç oluşturulması hedeflenmiştir. Deneyin ilerlemesi ile disperse olarak ayrışan grafit elektrotun boyutsal olarak küçüldüğü ve sistemden çekilen akımın azaldığı, bunun ise sürekli bir proses olma zorluğu ortaya çıkarabileceği tespit edilmiştir. Bunun için grafit çubuk sürekli olarak çözelti içine doğru ittirilmiş ve bu sayede toplam yüzey sabitlenmeye çalışılmıştır. Yine işlem sonucunda ayrışan karbon formları filtreleme, yıkama ve merkezkaç ile temizlenmiş ve ayrıştırılmıştır. Bu sayede $25 \mathrm{~V}-5 \mathrm{~A}$ çalışma formunda ne ideal Grafen layer formu elde edilmiştir. Grafenin karakterizasyonu FTIR, XRD, SEM, UVVis, Kararlılık Tayini gibi yöntemler Bruker Alpha Model 1003271/06 FTIR-ATR, Rigaku, Jeol 6000, Tescan Mira3 Shimadzu UV spektrofotometresi, Malvern Zetasizer Nano Z potansiyel cihazları ile tespit edilmiştir. Elektrokimyasal eksfoliasyon sonucu elde edilen koyu renkli dispersiyondan büyük ve kalın Grafen katmanlarının veya partiküllerini uzaklaştırmak için 20000 rpm' de 5 dakika boyunca yapılan santrifüj $6 \mathrm{kez}$ tekrar edilmiştir. Çökme hızını artırmak için santrifüj dönme hızı artırılmıştır. Nanoyapılar ve grafit partiküller sıvı süspansiyondan bariz çökelme hızıyla ayrılmışlardır. Dönme hızı ve santrifüj zamanı böylelikle farklı uygulamalar için grafit nanoyapılarının istenilen boyut dağılımını kesin bir şekilde kontrol etmek için ayarlanabilmektedir [14].

\subsection{Toz Metalürjisi İşlemleri ile Grafen takviyeli alaşım üretimi}

Grafen üretimini takiben yapılması gereken en önemli iş, Grafenin nasıl fonksiyonel bir bulk malzeme olarak kullanılmasını tespit etmektir. Bu noktada üretilen Grafenin dispersant bir sıvı içerisinde (Etanol) dağıtılmasını takiben bu sıvıya $\mathrm{Al}, \% 3 \mathrm{Mg}$ ve \%1 $\mathrm{Zr}$ (ağırlıkça) tozları ilave edilmiş ve bir miktarda PVA gibi polimer ilave edilmiştir. Grafen toplma metal ağırlığına oranla ağırlıkça \%0.05, 0.15, 0.3 ve 0,45 oranlarında ilave edilmiştir. Grafen, hexadecyl trimethyl ammonium bromide (CTAB) içeren etanollü çözeltiye ilave edilecek $20 \mathrm{dk}$ boyunca ultrasonik işleme tabi tutulup 1 saat manyetik olarak karıştırılmıştır. Burada zamanla hem sonik karıştırma hem de 1sıtma işlemi yapılmıştır. Buradaki amaç Grafenin sıvı bir faz içinde tamamen eksfoliye olmasıdır. Kurutma ile sıv1 faz buharlaşırken diğer $\mathrm{Al}, \mathrm{Mg}, \mathrm{Zr}$ metal tozları ile Grafen birbirini bir sarıp iyi bir dağılım göstermesi amaçlanmıştır. Nihayetinde tüm sıvı çözücü buharlaştığında çok iyi dağılmış Grafen ve metal tozları karışımı elde edilmiştir. Bu Kompozit karışım, artık toz metalürjisi adımlarına hazır hale gelmiştir. Bu aşamadan sonra tozlar farklı gramajlarda (1-10 g) pres kalıbına yerleştirilmişstir. Kalıplarda $15 \mathrm{~mm}$ ve $5 \mathrm{~mm}$ çapında numuneler üretilmiştir. Burada 200 MPA basınç uygulanmış, 5 dakika beklenmiş sonra numuneler çıkartılmıştır. Daha sonra azot gazı ile atmosfer koruması yapılan bir tüp firında $500-750{ }^{\circ} \mathrm{C}$ arasındaki sıcaklıklarda Sinterleme işlemleri yapılmıştır, işlem süresi 2 saat seçilmiştir. Sonrasında yoğunluk, mikroyapı, kesit inceleme, sertlik, XRD, elektron mikroskobisi, sürtünme deneyleri gerçekleştirilmiştir.

\section{BULGULAR}

Farklı gerilimler altında elektrokimyasal olarak ekfolye edilen grafit çubukların, elektrolit içine disperse edildikten sonra sırası ile belirtilen Grafen üretim rotası takip edilmiştir. Grafen üretimi için aşağıda verilen gerilim değerleri ve süreleri başlangıç kontrolleri için kullanılmıştır. Artan gerilim değerlerine karşılık zaman sabit tutulmuştur. 10 volttan daha düşük gerilimlerde eksfolye edilen Grafen tabakalarının sedimente olduğu ve ekstra asit ile açma işlemi gerektirdiği gözlenmiştir. Artan gerilim değerlerinin tepkisi öncelikle 300 Voltan aşağı doğru düşülmüştür. 300 voltan 80 volt değerine kadar olan aralıklarda katot üzerinde glow discharge formunda sparklar teşekkül etmiş bu ise grafit üzerinde mikro krater ve deforme grafit pulları şeklinde bir oluşuma sebep olmuştur. Bu nedenle $50 \mathrm{~V}$ dan daha yüksek gerilimlerde hem grafit pulları, tozları, pelteleri şeklinde düzensiz bir ekfoliye işlemi gerçekleşmektedir. 50 ve 30 gerilim değerlerinde ise üretilen grafit Grafen lamel formları daha makul ve stabil olmakla beraber $30 \mathrm{~V}$ gerilim değerleri üzerinde flokülasyon gerçekleşmiştir. $\mathrm{Bu}$ nedenle gerilim 
Aralığ 1 10-30 V arasında seçilmiştir, seçilen bu aralıkta ekfoliye edilen Grafen formlarının Zeta potansiyelleri Tablo 1.de verilmektedir. Ancak üretilen Grafen formlarında gerilim değerinin artması ile sonraki süreçlerde daha kararlı bir yapı elde emek için elektrokimyasal ekfoliasyon sürelerinin artırılması ve sisteme eş zamanlı sonikasyon eklenmesi sayesinde uygulanan gerilim değerlerinin azaltılması sağlanmıştır. $3 \mathrm{~V}$ gerilim 4 saat sürelerde grafit çubuklar yüksek bir verimle uygun zeta değerleri arasında kalmak kaydı ile elektrokimyasal yöntemle ile üretilebilmiştir.

Tablo 1. Gerilime karşı Zeta potansiyeli

\begin{tabular}{|c|c|c|}
\hline $\begin{array}{c}\text { Zeta Potasiyel } \\
(\mathrm{mV})\end{array}$ & $\begin{array}{c}\text { Uygulanan } \\
\text { Gerilim }(\mathrm{V})\end{array}$ & $\begin{array}{c}\text { Süre } \\
(\text { Saat })\end{array}$ \\
\hline Sediment & 10 & 0.5 saat \\
\hline $18-23$ & 15 & 0.5 saat \\
\hline $20-25$ & 20 & 0.5 saat \\
\hline $24-34$ & 25 & 0.5 saat \\
\hline Flocculation & 30 & 0.5 saat \\
\hline
\end{tabular}

Elektrokimyasal yöntemle üretilen Grafen ve Grafen oksit formları kendi içinde tasnif edilmiş, hatta klasik asit liçi ve $\mathrm{KMNO}_{4}$ (potasyumpermanganat) ilavesi ile yapılan indirgeme yöntemi ile kıyas edilmiştir. Buradan elde edilen Grafen formlarının UV-Vis spektrumları Şekil 2 de verilmektedir. $\mathrm{Bu}$ şekilde göre $260 \mathrm{~nm}$ dalga boylarında Grafen formları elektrokimyasal yöntemle üretilmiş ve öte yandan artan $\mathrm{KMNO}_{4}$ oranının ise yine indirgeme de etkin olduğu, piklerin şiddetinin artması ve sağa doğru kayması ile gözlenmiştir. Ancak yüksek oranlarda kullanılan permanganatın hem şiddetlerde azalmaya sebep olduğu hem de sonrası yıkama işlemlerinde ekstra temizleme süreci getirdiği bu süreç için bilinmektedir.

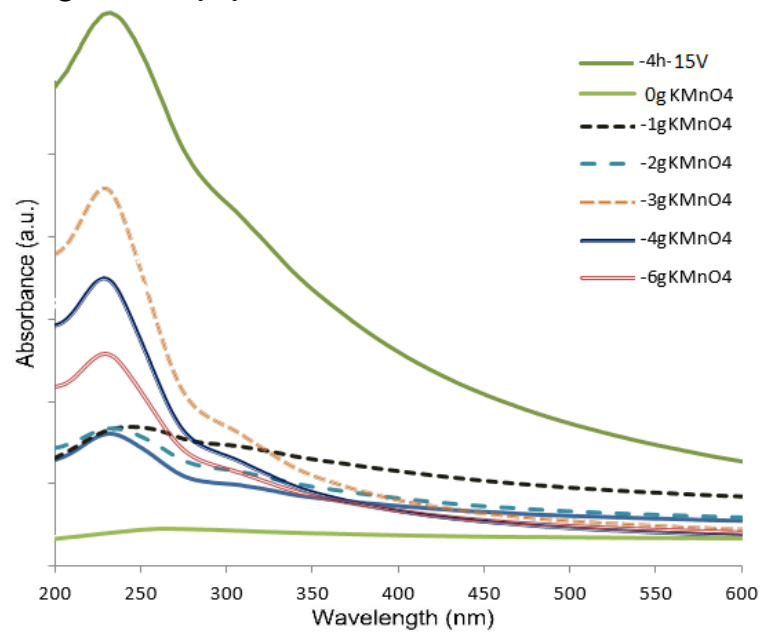

Şekil 2. Farklı KMNO4 içerikleri ile ve elektrolitik olarak üretilmiş Grafen yapılarının UV-Vis spektrumu.
Ayrıca sabit gerilim değerinde sürenin etkisi incelenmiş 30 dk ila 240 dakika arasında eksfoliasyon yapılmıştır. Sonuç olarak sabit gerilim altında artan işlem sürelerinde Grafen katmanlarının daha az olarak üretildiği ve UV-Vis absorban değerlerinde pik şiddetlerinin arttığı tespit edilmiştir.

Yukarıda yapılan çalışmalar elektrokimyasal olarak grafitten ekfolye edilen Grafenin geleneksel asidik ve indirgeme süreçli üretime alternatif olduğunu göstermektedir. Nitekim şekil 2 de 4 saat ve 15 volt gerilim altında yapılan çalışmalarda elde edilen Grafenin UV-Vis spektrasının yüksek şiddeti ve açılım hali karakteristik Grafen ve indirgenmiş Grafen formları ile uyum göstermiştir.

Uygulanan potansiyelin elektrokimyasal eksfoliasyonla elde edilen nanoyapılar üzerine etkisini incelemek amacıyla diğer koşullar sabit 10-100 V aralığında uygulanan potansiyelin etkisi gözlenmiştir. $10 \mathrm{~V}$ ' tan düşük potansiyellerin eksfoliasyon prosesi verimsiz olduğu $70 \mathrm{~V}$ potansiyelden daha yüksek potansiyellerde grafit elektrotların kısa sürede yüzeyde oluşan aşırı gerilim ve gaz çıkışına bağlı mikro ark ve spark oluşumu gözlenmiş ve elektrotlar hasar görmüştür, bu hasar elde dispersiyonda GO nano-parçacıklarının aglomere olması ve SEM ile yapılan yüzey incelemelerinde yüksek potansiyelin oluşan grafen oksit nano-yapılarında hasarlara ve plakalarda kırılmalara, açılan katmanların uç yüzeylerindeki gerilimin katlanma ve buruşma gibi hasarlara yol açması şeklindedir.

30-70 V aralığında ise elektrolitin 1sınma sürecinin hızlandığı ve verimin düştüğü kayıt edilmiştir. Verim hem üretilen Grafenin tartımı, hem grafit elektrot ağırlık kaybı hem de üretilen Grafen formlarının gerek fiziksel çökme testleri, UV Vis aralıkları ve Zeta potansiyelleri ile tespit edilmiş ve doğru üretim için hızlı deney-kontrol mekanizması tesis edilmiştir. Bu bilgiler 1şı̆̆ında tezde $20 \mathrm{~V}$ çalışma potansiyelinin en verimli olduğu kanaatine varılmıştır.

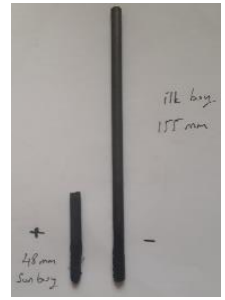

(a)

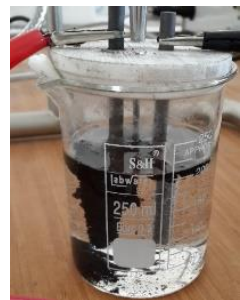

(b)

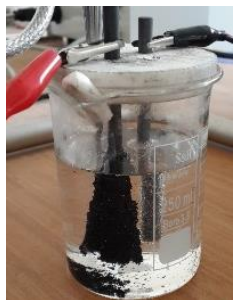

(c)
Şekil 3. (a) Elektrokimyasal Grafen eksfoliasyon öncesi 155 $\mathrm{mm}$ boyda olan iki elektrottan anodik etkileşime girendeki azalan grafit miktarı (b) $20 \mathrm{~V}$ gerilim altında anotta meydana gelen huni formunda grafit elektrotun açılması (c) $30 \mathrm{~V}$ gerilim altında anotta meydana gelen huni formunda grafit elektrotun açılması 


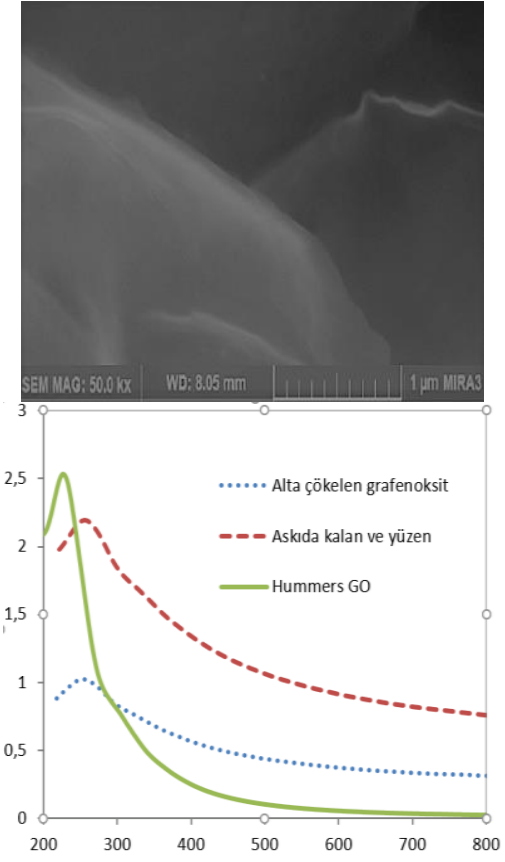

Şekil 4. $20 \mathrm{~V}$ gerilim altında ekfolye edilen Grafen formlarında beherin Alt kısmına çökelen, beherde askıda kalan, ve Hummer's ile üretilip askıda kalan Grafen yapılarının UV-Vis spektrumu ve Askıda kalan ve sonrası temizleme işlemlerinden geçen grafene ait elektron mikroskop görüntüsü

Şekil 4 ve verilen spektrumlarda elektrolitik yöntem ile üretilen ve askıda kalan Grafen formlarının UV-Vis spektralarının hafif sola doğru kaydığı ve Hummers ile üretilen Grafen kıyasla yukarı doğru çıktığı gözlemlenmiştir. $\mathrm{Bu}$ tür bir karakteristik eğrinin indirgenmiş ve birkaç tabaka Grafen spektrasına uyum gösterdiği düşünülmektedir. Aynı zamanda bu tür üretim yöntemlerinde üretilen ürün birçok farklı geometrik şekil gösterebilmektedir. Bazı durumlarda üretilen Grafen grafit elektrot yüzeyinden açılırken eğer ortam oksitleyici ise oluşan Grafenin oksitli olduğu, bazı durumlarda uygulanan parametreye bağlı ince grafit yaprakları, karbon tüp ve sarmallar, topaklanmış Grafen yumruları şeklinde olabilmektedir. Bazı durumlarda ise bu yapılar birlikte bulunmaktadır. Bu durumun tespiti ve Grafen formunun atomlar arası mesafe ve dizilimleri ile ilgili $\mathrm{X}$ 1şınları teknikleri kullanılmaktadır. Üretilen grafenlerin kristal yapısını karakterize etmek için XRD tekniği kullanılmıştır ve grafen/grafen oksit katmanlarının sayısı, tabaka ara mesafeleri ve kristal boyutlarının belirlenmesinde faydalı olmuştur. Farklı gerilimler eşit sürelerde üretilen ürünlere ait XRD grafikleri Şekil 5'de verilmektedir. Kıyaslama olması açısından başlangıçta kullanılan grafit elektrotun XRD grafiği de deneysel üretilen Grafen formları ile beraber sunulmuştur.

XRD tekniğinde gördüğümüz piklerin şiddetinin azalmas1, ters orantılı olarak d-mesafesinin arttığını göstermektedir. Ayrıca d-mesafesi arttıkça pik kısalıp genişlemekte, şiddeti düşmektedir, bu durum grafitin, grafit oksite ve sonrasında grafene dönüşmesi şeklinde tanımlanmaktadır. Şekil 5 de verilen pikler grafit için en şiddetli pikin 26.5 derece ve diğer şiddetli piklerin ise $2 \Theta 44$ ve 55 değerlerindedir. Grafen oksit olarak tanımlanan ve üretim sırasında oksitlenen Grafenoksit için karakteristik pik $2 \Theta 10$ derecede şiddetli bir pik ve 20-25 arası daha düşük şiddetli bir pikin eşliği şeklindedir (Lee 2017). Ancak Şekil 5 de $30 \mathrm{~V}$ gerilim altında üretilen Grafen oksit için anılan pikler ile beraber $2 \Theta$ 27 derecede bir pik de görülmektedir. Bu pik Lee ve arkadaşlarının yaptığ deney sirasinda elektrottan yer yer kopan nano grafit partiküllerinin tekrar ağlomere olmasında kaynaklı olduğu düşünülmektedir, yani $30 \mathrm{~V}$ gerilim altında yapılan çalışmada elektrolit içine bir miktar grafit veya $1 \mathrm{~nm}$ de kalın grafit yaprakları karışmış ve sonrasında ayrışmamıştır (Lee 2017).

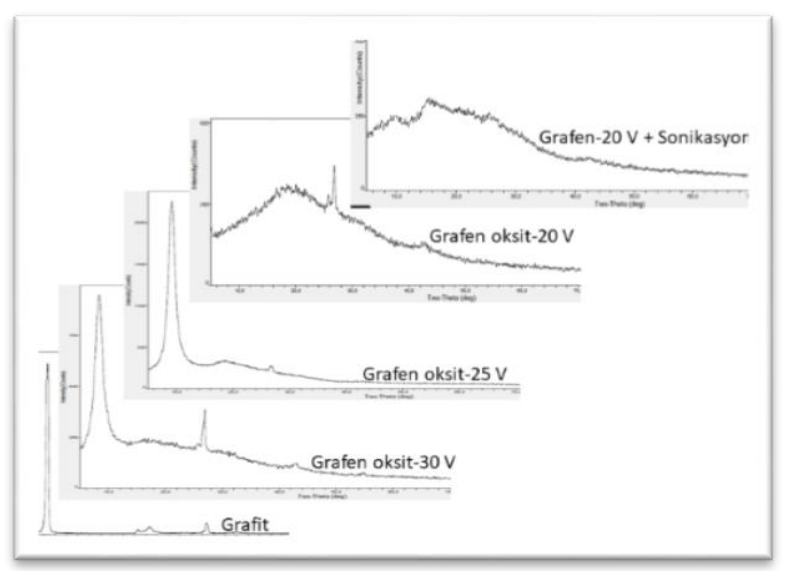

Şekil 5. Elektrolitik üretilen Grafen formalarının XRD grafikleri ve grafit ile karşılaştırılması

Uygulanan gerilim $25 \mathrm{~V}$ seviyesine gerilemesi ile mevcut grafit kirlenmesi azaltılmış ve x ışınları çekilen toz içindeki grafit seviyesi azalmıştır, bu durum ilgili grafit pikinin şiddetinin önemli seviyede azalması ile izah edilebilmektedir. Uygulanan gerilimin $20 \mathrm{~V}$ seviyesine düşmesi ile Grafen formu ciddi bir şekilde ortaya çıkmakta ve literatür ile uyumlu pikler elde edilmektedir. Bu sonuç gerilim azalması ile üretilen Grafenin daha az hatalı olduğuna işaret etmekle beraber yine bir miktar grafit katmanlarının olduğu anlaşılmaktadır. Ancak yine bu makalede denenen ve sürekli bir Grafen üretim prosesi olması için tasarlanan kademeli Sonikasyon işlemi ile tamamen Grafen formu üretilebilmiştir. $\mathrm{Bu}$ durum $20 \mathrm{v}$ gerilim ile beraber $1 / 10$ puls seviyesinde iki elektrot arasına \%75 güç ile Sonikasyon işlemi uygulanarak gerçekleşmiştir. $\mathrm{Bu}$ işlem ile iki elektrot arasında açılarak bir balerin eteği formuna dönüşen grafit elektrotların ara yüzeylerinde sıkışan ve gerekli iletim ve iyon iletimi sağlamama durumundan kaynaklandığı düşünülmektedir. Bu durumda Sonikasyon ile iki elektrot arasında sürekli elektrot bulunmakta ve ekfolye işlemi daha verimli hale gelmekte ve elektro ayrışmaya Sonikasyon asist etmektedir. Elbette multi layer grafenlerin de yine elektrolit içinde ayrışmasını da sağlamaktadır. Yapılan hesaplamalar sonucunda üretilen Grafenin ortalama $0.4 \mathrm{~nm}$ kalınlığında olduğu tespit edilmiştir, bu tespit için düzlemler arası mesafe ve XRD verileri kullanılmıştır. 
Üretilen Grafenin toz metalürjisi yöntemi ile bir bulk ürün haline getirilmesi işlemi gerçekleşmiştir. $\mathrm{Bu}$ işlemlerin detayları 2.2.

Toz Metalürjisi İşlemleri bölümde verilmiştir. İşlemler sonucunda üretilen ve $500^{\circ} \mathrm{C}$ derece ile $700{ }^{\circ} \mathrm{C}$ arasındaki sıcaklıklarda sinterlenmiştir bu işlemler 2 saat sürecinde argon atmosferi altında kontrollü ısıtma ve soğutma ile gerçekleştirilmiştir. Sinterleme için 4 farklı sıcaklık kullanılmış ve bu sıcaklıklarda numunelerin fiziksel olarak stabilitesi incelenmiştir. Sinterlemede argon seçimi hem alüminyum, magnezyum gibi son derece oksitlenme eğilimi yüksek tozların oksit formuna dönüşümünü engellemek hem de Grafen formunun oksit veya yanma ile boşluk yapısına dönmesini engellemektir.

Sinterleme sürecinde yapılan isıl işlemlerde maliyet ve mekanik özellik ikilisinin beraber optimum olduğu bir çalışma ve ürün kontrol stratejisi izlenmiştir. Sinterleme sıcaklığının $600{ }^{\circ} \mathrm{C}$ den yüksek olması durumunda, işlem süresinin kısalması gerekliliği aşikârdır. Nitekim 2 saat 700 ${ }^{\circ} \mathrm{C}$ yapılan Sinterleme sürecinde disk şeklinde basılan numunenin yanal bölgelerinde Şekil 6 da gösterilen türde dışa doğru sıvı metal basınç farkından kaynaklanan itici güç ile dış yüzey baloncuğu yapmış̦tır (Şekil 6), bu durum sinter sıcaklık veya süre parametrelerinin yüksek olduğu sonucunu akla getirmektedir $[15,16]$.

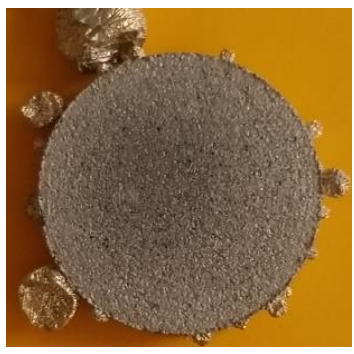

(a)

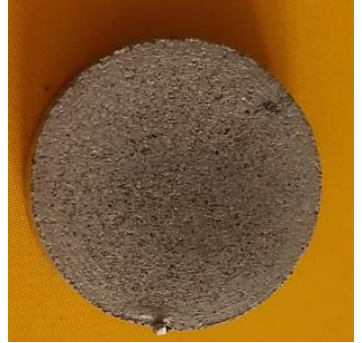

(b)
Şekil 6. (a) $700 \mathrm{C}$ de Sinterleme işlemi sonrasında numune yüzeyinde meydana gelen sıvı fazın oluşturduğu balon (b) Sinter sıcaklığının $100^{\circ} \mathrm{C}$ azalması ile baloncuk oluşumunun önlenmesi

Kapiler sıvı faz akışı ile dışa doğru oluşan bu balonun önlenmesi için işlem sicaklığ $1600^{\circ} \mathrm{C}$ ye düşürülmüsstür, bu sayede Şekil $6 \mathrm{~b}$ de görülen durum ortaya çıkmış ve balon oluşumu önlenmiştir. Sinterleme sicaklığındaki 100 derecelik düşüş Sinterleme süresini kısalmayı gerektirmemekle beraber, uzun Sinterleme sürelerinde şiddetli oksidasyon riski de bu sayede bertaraf edilmiştir.

Benzer şekilde numune et kalınlığının artırılması ile de benzer şekilde balon oluşumu önlenmiştir. Bu şekilde tespit edilen yüksek yoğunluklu numunelerin sertlikleri ve mekanik deneyleri icra edilmiştir ve sonuçlar Şekil 7 de verilmiştir.

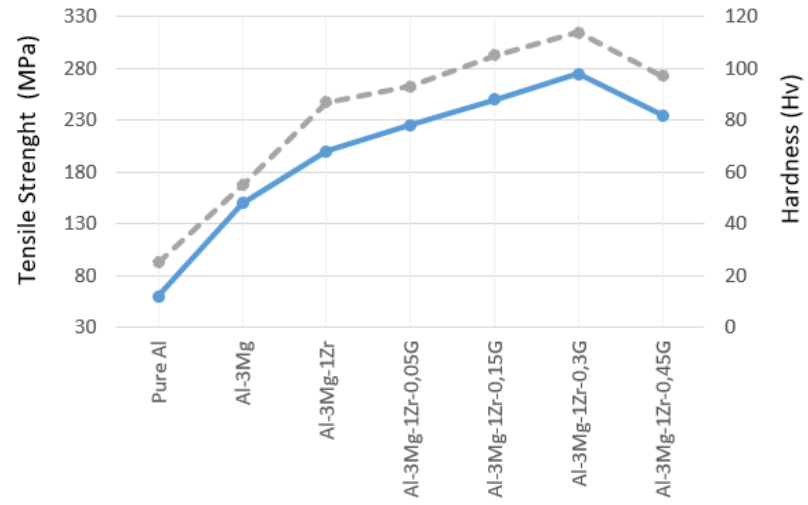

Şekil 7. Sinterlenen numunelerin sertlik ve çekme değerleri

Şekil 7, Sinterleme süresi, yoğunluk ve mekanik dayanım açısından optimize edilmiş ve $600-650^{\circ} \mathrm{C}$ de 2 saat argon altında sinterlenmiş numunelerin ortalama mekanik değerlerini göstermektedir. İlave edilen Grafen, Grafen oksit, çok duvarlı karbon nano tüp gibi bileşenlerin nanodolgu olarak takviye edilmesi ile mukavemet artırıcı görev yaptığı ve hatta ilave diğer bazı özelliklerinde geliştirmesinde fayda sağladığı düşünülmektedir. Literatürde, Grafenin bilyeli ögütme, sıcak pres ve sıcak ektrüzyon gibi yöntemler ile Kompozit üretiminde dahi iç özeliklerini kaybetmediği ve matris ile iyi bir bağlanma gösterdiği belirtilmiştir. $\mathrm{Bu}$ sayede mekanik özelliklerin arttığı ifade edilmiştir. Mekanik özelliklerin tespiti için kullanılan çekme testlerinde gerilim değerinin arttığı ve süneklikte ise kısmi bir artma olduğu gözlenmiş̧ir [17]. Şekil 7 de gösterilen çekme testinde de gerilim değerinin artan Grafen yüzdesi ile arttığı sonrasında ise tekrar azaldığ görülmüştür. Literatür bu noktada iki farklı test sonuçları arz etmektedir veya deneysel çalışmalar, ilave edilen Grafen yüzdesinin belirli bir yüzdeden sonra daha fazla ilave edilmediğini göstermektedir. Hongyan Yue ve arkadaşları yaptıkları çalışmada bakıra \%ağ. $0,5,1$ ve 2 grafen ilave etmişler ve $\% 1$ ve daha fazlasının hem çekme deneyinde gerilme ve gerinme değerini hem de sertliği düşürdüğünü ölçmüşlerdir [18]. Yaptı̆̆ımız çalışma yine Hongyan ve arkadaşlarının sonuçlarına benzer şekilde eğilim göstermiştir. Sünek $\% 0.3$ grafen ilave seviyesine kadar sertlik ve mukavemet artarken daha yüksek seviyelerde ilave edilen Grafen miktarı için mekanik özellikler gerileme göstermiştir. AlMg1Zr+0.15 Grafen kodu ile gösterilen numuneye ait elektron mikroskop görüntüleri Şekil 8 de verilmektedir. Şekil 8a. SE mod ve sinter sonrası yüzey, Şekil 8.b de ise mekanik test sirasında kırılan numuneye ait kırık yüzey görüntüleri verilmiştir. Bu SEM görüntüleri Sinterleme ile tanelerin birbirine mekanik olarak ve metalürjik olarak iyi bir kenetleme yaptığını ve Grafen nano formların tane sınırlarında kaymayı engelleyici ve ayn zamanda kayma yönünün değiştirilmesi için yağlayıcı etki yaptığı düşünülmektedir. Şekil 8B ile gösterilen resimde ise yine sünek bir davranış emaresi olan küçük kraterler oluşmaktadır. Bu durum gerilim ile beraber sünekliğin de paralel arttığının akla getirmektedir. Metal matris içerisindeki al, mg ve zr tozlarının gerek soğuk presleme ve gerekse Sinterleme sirasinda Grafen ile muntazam bir 
şekilde sarılarak ve özellikler pres esnasında oluşan basınca bağlı olarak Grafenin metal tozlar arasındaki boşlukları doldurmak sureti ile mikro yapıyı daha yoğun hale getirmektedir.

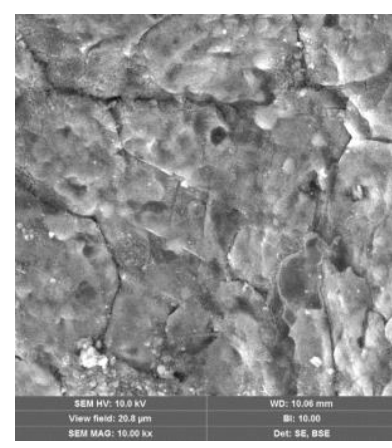

(a)

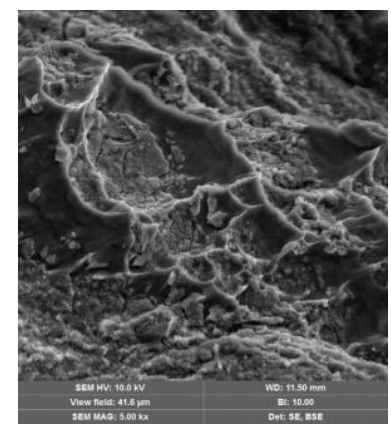

(b)
Şekil 8. Sinterleme işlemi sorası tane ve alt tanelere ait elektron mikroskop görüntüsü ve kırık yüzey görüntüsü $\mathrm{Bu}$ durum ise mekanik etkisi sırasında tanelerin kaymasını önleyerek gerilim değerini artırmaktadır benzer yaklaşım sertlik ölçümü için de geçerlidir. Grafenin mikro yapıda diğer metalik taneleri çepeçevre sarmasına ve dolgu olarak görev yapmasına bir yaklaşım olarak Şekil 9 da verilmektedir.

Şekil 9. da Grafenin bir uygun bir açıcıda açılması sonrasında ve Kompozit imalatı sırasında metal tozlarının etrafına sarılmasına ait görüntüler verilmiştir. Grafenin metal etrafına veya kavşaklara homojen bir şekilde yerleşmesi arzu edilmekte nitekim bu işlem mekanik, fiziksel ve termal özellikleri dahi artırmaktadır. Ancak bu işlem için de bir optimizasyon değeri tespit etmek gerekli olacaktır. Belirli bir seviye sonrası ilave edilen Grafen mekanik özelliklerin düşmesine ve hatta başlangıç alaşım değerlerinden daha düşük seviyelere gerilemesine sebep olabilmektedir. Bu durum gerilme değerinden ölçüleceği gibi kırık yüzeyden de mikro yapı tekstürünün değişmesi şeklinde de anlaşılmaktadır [18].

Yapılan çalışmada da Grafenin artan oranlarının matris tozları arasında homojen bir şekilde dağılma zorluğu ise karşılaşılan bir diğer mühendislik problemidir. Genel olarak mühendislik anlamda sorunsuz bir Kompozit imalatı yapıldığı varsayılırsa, mukavemetin artış sebebi a) Orowan dayanımı, b) tane inceltme, c) dislokasyon jeneratörü, d) yük aktarımı prensipleri ile izah edilmektedir. Grafenin partikül etrafina sarılması Sinterleme sırasında sınır göçünü engelleyerek tane büyümesini önlemektedir. Benzer şekilde Grafenin yaptığı arayüzey bağı ise yükleme sırasında yükün bu arayüzeydeki bir köprü misali aktarılmasına neden olmakta ve dayanıma etki etmektedir. Ancak ilave edilen fazla miktarda Grafen ise aglomerasyon yaparak, matrisin kırılmasını gevrek bir kırılma davranışı şekline çevirmektedir. Ancak bu olumsuz yönün yanında, tesadüfi olarak artan Grafen oranının sıkıştırılma için gerekli toplam işin azalmasına yol açtığı tespit edilmiştir.

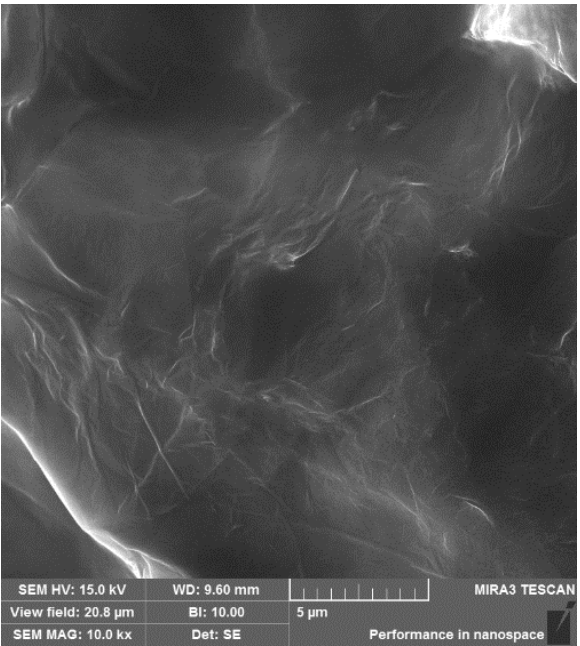

(a)

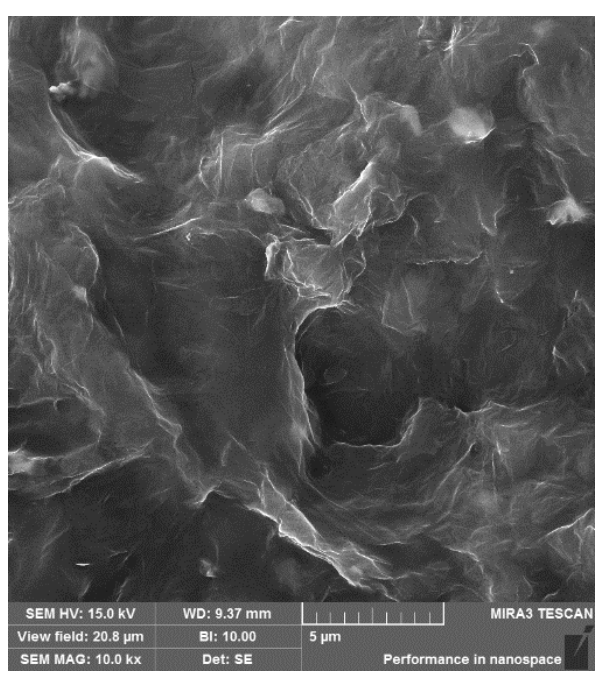

(b)

Şekil 9. Grafen nano-karbon fillerlara ait SEM görüntüleri (a),(b)

$\mathrm{Bu}$ durum ise yüksek yüklerde sıkıştırılan metalin kalıp içinde hareketinden dolayı kalıp duvarlarına uyguladığı basınç, karşı hareket ile sürtünme kuvvetlerinde azalmaya neden olmuştur. Bu deney düşük yüklü aşınma cihazından ölçülmüş aşınma direncinin arttığı, sürtünme kuvvetinin azaldığı anlaşılmıştır. Ancak bu konu başka bir makale konusu olarak irdelenecektir. Ancak, yüksek basınlar altında Grafenin yağlama etkisinin olduğu, toplam sıkıştırılabilirligin \%10 arttığı tespit edilmiştir. Grafen ilave edilmiş numunenin yüksek sıcaklıklarda sinterlenmesi neticesinde mekanik özelliklerin olumsuz etkilendiği fiziksel incelemeler sonucunda anlaşılmıştır. Sinterleme işlemlerinde süpürme gazı olarak azotun da kullanılabileceği, bu durumda boşluğun daha da azaldığ Arşimet deneyi ile tespit edilmiştir.

\section{DEĞERLENDİRME VE SONUÇLAR}

Yeni nesil elektrokimyasal ayrıştırma yöntemi ile klasik yöntemlere nazaran, son derece hızlı ve ekonomik bir Grafen üretim sistemi geliştirilmiştir. Elektrolit olarak kirlilik arz 
etmeyecek elektrolitler ve Grafenin kendisi kullanılmıştır. Anodik ve katodik çözündürme yapılmış anodik çözündürmede verimin daha yüksek olduğu ancak oksitlenmenin de mümkün olduğu anlaşılmıştır. 20-25 V gerilim altında $30 \mathrm{dk}$. Sürelerde Grafen üretildiği anlaşılmıştır. Basit bir ayrıştırma ile üretilen Grafenin ideal özelliklere yaklaştığ görülmüştür.

Alüminyum metali önce magnezyum ile alaşımlanmış ve sonrasında zirkonyum ile mekanik özellikler artırılırmıştır. Sonrasında bu 3 lü alaşım Grafen takviyeli Al-Mg-Zr hafif metal Kompozit alaşımı haline, soğuk baskı ve akabinde atmosfer kontrollü Sinterleme işlemleri rutininde getirilmiştir.

\% 0.3 grafen ilave edilmiş 3 lü alaşımda mekanik özelliklerin pik yaptığı artan değeler için, bu yöntemde olumsuz bir etki başlangıç gösterdiği gözlenmiştir.

Sinterleme sıcaklığının $600-650{ }^{\circ} \mathrm{C}$ aralığında olması, mühendislik anlamda en ideal yanıtı vermiştir.

\section{TEŞEKKÜR}

Bu proje, Sivas Cumhuriyet Üniversitesi, BAP tarafindan, Alüminyum-Magnezyum Alaşımlarına Nano-Karbon Türevli Takviyelerin Etkisi başlıklı ve M-627 numaralı proje ile desteklenmiştir.

Ayrıca makalede destek veren Merve Sarı, Kübra İnce, Dr. Ali Özer, Duygu Anaklı ve diğer Cumhuriyet Üniversitesi Bölüm Mensuplarına teşekkür ederim.

\section{KAYNAKÇA}

[1] S.C. Tjong "Recent progress in the development and properties of novel metal matrix nanocomposites reinforced with carbon nanotubes and graphene nanosheets" Materials Science and Engineering R 74 281-350, 2013

[2] L. Liu, D. Ren and F. Liu, "A Review of Dissimilar Welding Techniques for Magnesium Alloys to Aluminum Alloys", $\quad$ Materials, $\quad$ 7(5), 3735-3757; doi:10.3390/ma7053735, 2014

[3] H. Haferkamp, M. Niemeyer, U. Dilthey, G. Trager, "Laser and electron beam welding of magnesium materials". Weld. Cutt,,52, 178-180. 2000

[4] G. Yarkadaş, L.C. Kumruoğlu, H. Şevik, "The effect of Cerium addition on microstructure and mechanical properties of high pressure die cast Mg-5Sn alloy" Materials Characterization Volume 136, , Pages 152-156, February 2018

[5] G.S. Ashuri. M. Emamy, M. Bidel, F. Khoshsout "Effect of $\mathrm{Mn}$ alloy element on microstructural features and mechanical performance of $\mathrm{Al}-6 \% \mathrm{Mg}$ commercial casting alloy" Conference 9th Joint Congress of Iranian Metallurgical Engineering society \& Iranian Foundrimans society At: İran DOI10.13140/RG.2.1.1464.6646 (November 2015)

[6] T. Morishigea, T. Hiratab, T. Uesugia, Y. Takigawaa,
M. Tsujikawaa, H. Higashia, "Effect of Mg content on the minimum grain size of $\mathrm{Al}-\mathrm{Mg}$ alloys obtained by friction stir processing" Scripta Materialia Volume 64, Issue 4, Pages 355-35, February 2011

[7] H. Guang, L. Xiangfa, D. Haimin "Grain refinement of $\mathrm{Mg}-\mathrm{Al}$ based alloys by a new Al-C master alloy" Journal of Alloys and Compounds, Volume 467, Issues 1-2, 7, Pages 202-207, January 2009

[8] H. Y. Nan, Z. H. Ni, J. Wang, Z. Zafar, Z. Xiang S. Ying Wang, "The thermal stability of graphene in air investigated by Raman spectroscopy" https://doi.org/10.1002/jrs.4312,29 April 2013

[9] C.T.J. Low., F.C. Walsh, M.H Chakrabarti. M.A. Hashim, M.A. Hussain, "Electrochemical approaches to the production of graphene flakes and their potantial applications", Carbon, 54, 1-21, (2013)

[10] B.Y. Zhu, S. Murali, W. Cai, X. Li, J.W. Suk, J.R. Potts, R.S. Ruof, "Graphene and Graphene Oxide: Synthesis, Properties, and Applications", Adv. Mater., 22, 3906-3924, (2010).

[11] G.M. Morales, P. Schifani, G. Ellis, C. Ballesteros, G. Martinez, C. Barbero H.J. Salavagione, "High-quality few layer graphene produced by electrochemical intercalation and microwave-assisted expansion of graphite", Carbon, 49, 2809-2816, (2011).

[12] Y. Matsumoto, H. Tateishi, M Koinuma, Y. Kamei, C. Ogata, K. Gezuhara, K. Hatakeyama, S. Hayami, T. Taniguchi, A. Funatsu, "Electrolytic graphene oxide and its electrochemical properties", Electro. Chem., 704, 233-241, (2013).

[13] C.Y. Su, A.Y. Lu, Y. Xu, F.R. Chen, A.N. Khlobystov, L.J. Li, "High quality thin graphene films from fast electrochemical exfoliation”, ACSNANO, 5 (3), 2332-2339, (2011)

[14] C.Y. Yang, C.L. Wu, Y.H. Lin, L.H. Tsai, Y.C. Chi, J.H. Chang, C.I. Wu, H.K. Tsai, D.P. Tsai, ve G.R. Lin, "Fabricating graphite nano-sheet powder by slow electrochemical exfoliation of large-scale graphite foil as a mode-locker for fiber lasers". OSA Publishing, 3, 17922002. (2013).

[15] H. C. Lee et al. "Review of the synthesis, transfer, characterization and growth mechanisms of single and multilayer graphene" RSC Advances 7(26):1564415693DOI:10.1039/C7RA00392G, March 2017

[16] R. Surace, L.A.C. De Filippis, A.D. Ludovico, G. Boghetich "Influence of processing parameters on aluminium foam produced by space holder technique" Materials and Design 30, 1878-1885, (2009)

[17] S.J. Yan et al, "Investigating aluminum alloy reinforced by graphene nanoflakes",. Materials Science \& Engineering A 612, 440-444, (2014)

[18] H. Yue et. al. "Effect of ball-milling and graphene contents on the mechanical properties and fracture mechanisms of graphene nanosheets reinforced copper matrix composites", Journal of Alloys and Compounds 691, 755-762, (2017) 